\title{
Política, gênero e sujeito: afinidades com conseqüências*
}

\section{Claudia Fonseca*}

Em 17 de novembro, 2001, a Primeira Dama dos Estados Unidos, Laura Bush, juntou sua voz, enquanto mulher, à de seu marido num apelo radiofônico a favor da invasão americana de Afeganistão:

Graças a nossas vitórias militares recentes no Afeganistão, as mulheres não são mais encarceradas nas suas casas. Podem escutar música e educar suas filhas sem medo de castigo... A luta contra o terrorismo também é uma luta pelos direitos e a dignidade de mulheres. ${ }^{1}$

Lila Abu-Lughod, um antropóloga da Universidade de Columbia, cita esse episódio para dar corpo a sua inquietação quanto a certos usos simplistas do feminismo. Sublinhando a extrema ironia do enunciado de Sra. Bush, representante de um governo que tudo fez para consolidar o poder do Talibâ no Afeganistão, Abu-Lughod questiona suas colegas, acadêmicas feministas, pelas "alianças esquisitas" (strange bedfellows) que travam ao promover, acima de tudo, a causa comum da "mulher". Já tendo elaborado sérias críticas ao relativismo

\footnotetext{
"Resenha de AlmeidA, Heloisa B.; CostA, Rosely G.; RAmireZ, Martha C. e SouzA, Erica R. de. (orgs.) Gênero em Matizes. Bragança Paulista, Coleção Estudos CDAPH, 2002. Recebida para publicação em setembro de 2003.

** Programa de Pós Graduação em Antropologia, Universidade Federal do Rio Grande do Sul.

1 apud ABU-LUGHOD, Lila. Do Muslim women really need saving: anthropological reflections on cultural relativism and its others. American Anthropologist 104(3), 2002, p.784. [Tradução das citações: Claudia Fonseca.]
} 
Política, gênero e sujeito

cultural, essa autora, com o peso de suas origens palestinas $e$ longos anos de pesquisa no Egito, lança o desafio a seus leitores ocidentais: "Do Muslim women really need saving?"2

Afinal das contas, o problema político-ético apontado pelo uso do véu (...) é como lidar com esses culturalmente "outros"? Como lidar com a diferença sem aceitar a passividade sugerida pelo (compreensivelmente maufamado) relativismo cultural (...)? Desconfiança quanto a "aliados esquisitos" é apenas o primeiro passo. [Essa desconfiança] não nos ajudará a pensar positivamente sobre o que fazer ou a onde nos posicionar. Para isso, precisamos confrontar dois grandes desafios: Primeiro: aceitar a possibilidade de diferença. Devemos "liberar" as mulheres afegãs apenas para elas poderem ser como nós? Ou devemos reconhecer que, mesmo depois da "liberação" do Talibã, talvez queiram coisas diferentes daquelas que nós estimamos melhores para elas? $\mathrm{O}$ que fazemos com isso? Em segundo lugar, precisamos exercer muita vigilância quanto à retórica da salvação e suas implicações no que concerne nossas próprias atitudes. ${ }^{3}$

O artigo de Abu-Lughod é apenas a ponto do iceberg de um debate que existe há mais de trinta anos entre ativistas $e$ acadêmicos que estudam gênero e/ou mulher. ${ }^{4}$ A coletânea, Gênero em Matizes, surge no bojo dessa discussão, com bibliografia altamente atualizada, cobrindo os últimos desenvolvimentos na teoria feminista. Fruto de uma longa reflexão por pós-graduandos da Unicamp, e partindo de trocas intensas

\footnotetext{
${ }^{2}$ ID., IB.

3 ID., IB., pp.786-787.

${ }^{4}$ STRATHERn, Marilyn. The Gender of the Gift. problems with women and problems with society in Melanesia. Berkeley, University of California Press, 1988; ORTNER, Sherry B. Making Gender. the politics and erotics of culture. Boston, Beacon Press, 1996; PISCITElli, Adriana. Re-criando a (categoria) mulher. Textos Didáticos 48: a prática feminista e o conceito de gênero [Leila M Algranti, org.], Campinas, IFCH-Unicamp, 2002.
} 
com pesquisadoras ligadas ao Núcleo de Estudos de Gênero/Pagu (Mariza Corrêa, Suely Kofes, Marilyn Strathern...), essa coletânea de artigos dá mostra de uma admirável coerência interna. Análises teóricas sofisticadas, centradas em autoras como Judith Butler, Donna Haraway, Tereza de Lauretis (entre muitas outras), são completadas por estudos etnográficos - sobre prostitutas, jovens mães, educadoras, sindicalistas negras... -, que demonstram a grande relevância dessas teorias para a compreensão do mundo contemporâneo.

Como toda reflexão acadêmica de qualidade, as idéias levantadas nesse volume têm muitos desdobramentos possíveis, indo muito além do campo de gênero. No curto espaço dessa resenha, proponho me centrar num tema, discutido em diversos artigos, e retomado pela pesquisadora experiente, autora do epílogo - Verena Stolke: a tensão que decorre do confronto entre a perspectiva feminista que lança mão de "políticas de identidade" (identity politics) para combater a injustiça, $e$ a análise intelectual, desconstrucionista, muitas vezes classificada como "pós-moderna", que tende a esvaziar justamente as categorias identitárias que os ativistas tanto prezam. Entre as outras inquietações que levanta, Stolke dá voz a uma dúvida, comum no campo de estudos de gênero, quanto ao chamado "elogio das diferenças": ao clamar de forma quase obsessiva por uma multiplicidade de diferenças de sexo (de opção sexual, de anatomia genital, de gênero e de subjetividade), os adeptos dessa tendência não estariam minando as afinidades políticas entre mulheres e dificultando a demanda por uma redistribuição igualitária de poder (p. 403)? Trata-se da mesma pergunta que tem levado pesquisadores a recuar de "gênero" e voltar para um conceito atualizado de "mulher" - isto é, que incorpora a sofisticação teórica de recentes debates. ${ }^{5}$

$\mathrm{O}$ interessante desse volume é que justamente essa pergunta - que permanece implícita em muitos trabalhos sobre gênero - é

${ }^{5}$ Piscitelli, A. Re-criando a (categoria) mulher. Op. cit. 
Política, gênero e sujeito

enfrentada de modo claro e provocador em diversos dos artigos. Simião, no primeiro trabalho da coletânea faz entrevistas entre ONGs (algumas feministas, outras não) do Rio de Janeiro, São Paulo e Curitiba para entender exatamente como as novas teorias de gênero estão influenciando a atuação dessas entidades nas áreas de educação, saúde, e combate à violência. Descobre que, tal como é ressignificado por essas organizações, o termo "gênero" não substitui a categoria "mulher" (acionada para questões tais como "violência contra a mulher", etc.), mas serve antes para garantir a transversalidade do tema entre as diferentes organizações. Retomando a história desse campo, o autor mostra como a idéia gênero/cidadania (em vez da anterior mulher/ desenvolvimento) permite "uma política de alianças das ONGs especialmente as feministas - com outros setores da sociedade" (p.33). Dessa forma, a reflexão sobre relações de gênero e o combate às diferentes formas de discriminação $e$ violência de gênero passam a ser preocupações de um leque maior de organizações - que sejam feministas ou não.

Costa, lembrando que, para antropólogos, o "outro" é geralmente interlocutor antes do que adversário, também discorre sobre a tensão entre militantes (que pensam em termos de desigualdade) e acadêmicos (que, além da desigualdade, pensam em termos de assimetria e complementaridade). Esse tema surge das suas considerações sobre os atuais estudos de masculinidade $e$, em particular, sobre os críticos a esse campo. Entres outras objeções, estes sugerem que a nova ênfase analítica no homem arrisca diluir a atenção atribuída às mulheres (recém saídas da "invisibilidade"), provocando uma despolitização do campo feminista. Em resposta, Costa, assim como outros autores desse volume, ressalta as profundas repercussões, inclusive políticas, das novas teorias do sujeito exemplificadas em autoras tais como Butler e Haraway. Examinado à luz das novas teorias do sujeito, o adversário imaginado por feministas tradicionais isto é, o homem, ou pelo menos "o modelo hegemônico de masculinidade" - perde sua nitidez. A observação da realidade 
revela pessoas com trajetórias diversas, achando o caminho entre modelos diferentes de masculinidade, cada qual em disputa pelo status hegemônico. Monteiro retoma essa discussão, ampliando as referências para diversos trabalhos etnográficos da masculinidade, para explorar as sutilezas da "teoria queer", reiterando as críticas feitas por essa corrente a noções conservadoras de essência, identidade, naturalidade, e heterossexualidade compulsória.

Hita liga as teorias do sujeito à história do feminismo, citando S. Friedman, para lembrar o quanto o conflito entre determinados atores sociais (feministas brancas de classe média debatendo com mulheres de cor e outras categorias "minoritárias") influenciou a evolução dos conceitos: da ênfase na "diferença" para a apreciação das "diferenças" e a ressignificação da própria igualdade. Insistindo em noções analíticas mais flexíveis do que a antiga categoria "identidade", estes autores trabalham com a idéia de "coalizões", "afinidades", ou "convergências" entre "posicionalidades relacionais" para acentuar o caráter dinâmico e complexo do sujeito moderno. Assim, a identidade "mulher" opera ao lado de outras (e, dependendo do contexto, mais relevantes) categorias identitárias - de classe, etnia, religião, orientação sexual, etc. - categorias estas que o pesquisador não pode ignorar, sob risco de reificar seu objeto - a complexa realidade em que vivemos.

Em pesquisas empíricas de assuntos controvertidos, os vários artigos de Gênero em Matizes oferecem exemplos desse olhar teórico inovador. Levando ao cabo as implicações das novas teorias do sujeito, Pacheco explora a subjetividade de Zeferina mulher, negra, e empregada doméstica - que, ao despertar para a liderança sindical, passa a repensar suas solidariedades de raça $e$ gênero, consolidando a primeira e subtilizando a segunda. $\mathrm{Na}$ análise de Souza de uma turma escolar de pré-adolescentes as estratégias pedagógicas das professoras são analisadas à luz de cor, geração e classe. No relacionamento entre jovens do grupo, assim como na interação deles com a professora, descobre-se também o ponto de vista dos alunos - em particular, como 
Política, gênero e sujeito

estereótipos de raça, corpo e gênero são recebidos e remanejados nos seus conflitos, formas de agressividade e definição de práticas esportivas "masculinas" e "femininas". Transportando o leitor para uma população levemente mais velha, Camboim questiona a própria noção de "juventude" ao constatar como as "mães novinhas" em bairros populares do Rio Grande do Sul afastam-se das imagens bio-médicas de "gravidez na adolescência". Aqui, como nos outros artigos citados, gênero permanece um foco central, mas esse recorte só adquire sentido quando pensado a partir da interação entre atores concretos, com idade, cor e classe. Assim, sofistica-se a análise de temas politicamente relevantes (educação, violência, gravidez, organização sindical...) sem ceder à tentação de aplicar as táticas de identity politics fora de lugar.

De forma semelhante, Ramirez, ao sublinhar a pluralização de noções de masculino e feminino, fala da tendência entre teóricos do campo a redimensionar o conceito de poder. Sugere, no entanto, que, embora Butler e seus congêneres tenham provocado uma revolução na percepção da sexualidade (hetero, em particular), ainda têm sido tímidas na desconstrução de noções de reprodução. Ao tratar desse tema, as feministas freqüentemente colocam o corpo da mulher como "site de resistência", indiretamente reforçando as visões naturalista $e$ essencialista que, em outras instâncias, tanto tentam combater. Para apontar as falhas desse raciocínio, Ramirez, assim como Stolke, volta-se para a análise das novas tecnologias reprodutivas. Estas demonstrariam de forma concreta como, longe de ser o último reduto da natureza, a reprodução é um processo fundamentalmente social.

Uziel, na sua reflexão sobre a adoção por homossexuais, também contesta perspectivas usuais da reprodução. Na sua consideração das atitudes dos diferentes atores do campo jurídico, a autora acaba questionando não somente as imagens do masculino e feminino, mas da própria "família". Mostra como estereótipos de gênero e, em particular, a estreita associação de "família" com o casamento heterossexual subjazem o preconceito 
contra homossexuais e solteiros que aspiram ao status de pai adotivo. No mesmo espirito, Pasini aproveita sua pesquisa entre profissionais de sexo na cidade de São Paulo para refletir sobre o corpo construído como locus de significados. Aqui, a relação sexual - fonte potencial tanto da doença quanto da concepção assume significações inteiramente diversas conforme o teor da relação entre a prostituta e seu parceiro. Que sejam mulheres com identidade hetero ou homossexual, a camisinha é ostentada como demarcadora fundamental de fronteiras entre o mundo de trabalho e o mundo de afeto.

Finalmente, a partir da imersão total no campo etnográfico, Motta e Almeida, cada qual, a sua maneira demonstram a variabilidade das atribuições de gênero. Motta, reflete sobre a relação entre homens e animais no litoral catarinense para ilustrar a arbitrariedade das definições do masculino e feminino. Da evitação da arraia (peixe que "menstrua") e a brincadeira na farra do boi até o investimento afetivo e financeiro nos curiós, vemos como os ilhéus fazem a "sexagem" do universo. Trata-se de uma estruturação do mundo que é perpassado por imagens sexuais. Porém, nas mãos hábeis dessa etnógrafa, vemos como essas imagens, longe de serem fixas ou rígidas, refletem as relações de gênero - diversas e fluídas - da vida social. Almeida, por outro lado, descreve os percalços metodológicos de uma pesquisadora mulher, casada, citadina - tentando se imiscuir na vida cotidiana de uma cidade interiorana de Minas Gerais. Na comparação com a experiência de pesquisadores em outros campos (Abu-Lugod em Marrocos, Almeida no Portugal, Landes em Bahia...), ela não somente explora a maneira como é recebida pelos "nativos" (ora como mulher, ora como forasteira assimilada ao mundo masculino...), mas também volta o olhar analítico para sua própria subjetividade, mostrando esta como o resultado de uma negociação com uma complexa realidade.

Em suma, esse volume reflete os avanços do feliz casamento que ocorreu nos últimos anos entre feministas politicamente engajados e a teoria analítica da mais alta qualidade. Devemos 
Política, gênero e sujeito

lembrar que, em 1988, M. Strathern, ao escrever sobre a antropologia feminista, ainda lamentava a falta de sofisticação teórica deste campo. Sem fazer a distinção entre ativistas e teóricos, acusava as antropólogas feministas de "conservadorismo conceitual", reconhecendo que, para alcançar seus objetivos políticos, estas eram praticamente obrigadas a simplificar suas análises e ceder a uma visão reificada da mulher. É só na década de 90 que surgiu uma nova geração de teóricas feministas (Butler, De Lauretis, Haraway) que vieram dialogar com a ala mais rica da antropologia feminista (Collier, Yanagisako, Rapp, Ginsburg... e a própria Strathern), consolidando um movimento altamente politizado da vanguarda intelectual. Ironicamente, o cismo comentado por Strathern (entre acadêmicos feministas e acadêmicos tout court) se desloca agora para a fronteira entre acadêmicas feministas e ativistas extra-acadêmicas. Hartmann et alii, por exemplo, descrevem o "desgosto" com que muitas feministas olham atualmente para o campo acadêmico. Queixando-se das discussões teóricas "inacessíveis, esotéricas, de difícil compreensão, excessivamente destacadas da prática e conduzindo a uma paralisia" ${ }^{6}$, certas delas se afastaram das discussões universitárias afirmando que se "no passado, foram teóricas E ativistas [...] no presente, sentem-se apenas ativistas". ${ }^{7}$

Gênero em Matizes é um livro sensível a esses dilemas colocados pelos recentes deslocamentos no campo da teoria e do ativismo feministas. Os autores desse volume, comunicando para o leitor os pontos principais da história do debate entre acadêmicos e ativistas - os momentos chave na evolução da militância feminista no Brasil, assim como dos conceitos empregados na análise acadêmica - não são ingênuos. Não minimizam a eficácia estratégica de "identity politics" no campo político, mas apresentam um argumento persuasivo, sugerindo que, sem lançar mão dos instrumentos teóricos desenvolvidos pela

${ }^{6}$ apud Piscitelli, A. Re-criando a (categoria) mulher. Op. cit., p.33.

7 ID., IB. 
vanguarda dos estudos de gênero, o pesquisador arrisca se desviar de sua missão principal: oferecer perspectivas originais $e$ reveladoras de nossa realidade. Dessa forma, a proposta implícita do livro não difere muito da recomendação feita por Abu-Lughod na sua discussão provocadora sobre mulheres muçulmanas. A preocupação política - que inclui a justiça para mulheres - se mantém como uma premissa básica da pesquisa, mas trata-se de uma preocupação que só adquire sentido quando considerada em situações concretas, mediada pelas subjetividades variantes produzidas em contextos históricos específicos. Exige do pesquisador o "trabalho árduo envolvido no reconhecimento $e$ respeito às diferenças, vistas como produtos de histórias diversas, expressões de circunstâncias particulares, e manifestações de desejos estruturados variavelmente $"{ }^{8} \mathrm{Na}$ medida em que teóricos $e$ ativistas estiverem prontos a juntar forças para realizar essa agenda, o conceito de gênero (em matizes) permanecerá como orientação importante de trabalho tanto acadêmico como político.

8 ABU-LUGHOD, L. Do Muslim women really need saving... Op. cit., p.787. 